\title{
Shape Anisotropy Evolution of Co Grains in Cu-30at\%Co Alloy by Annealing under Magnetic Field
}

\author{
Hideyuki YASUDA, Yasutaka YAMAMOTO, Itsuo OHNAKA and Kohji KISHIO") \\ Department of Adaptive Machine Systems, Osaka University, Osaka 565-0871 Japan. \\ 1) Department of Applied Chemistry, University of Tokyo, Tokyo 113-8656 Japan.
}

(Received on December 10, 2002; accepted in final form on March 6, 2003)

\begin{abstract}
The shape change of the fcc-Co grains during the coarsening process was examined by using the $\mathrm{Cu}-$ 30 at\% Co alloys. The fine Co-rich particles were uniformly distributed in the rapidly solidified alloys when the cooling rate was sufficiently large to prevent the dendritic growth of the primary Co phase. The influence of the magnetic field on the shape change of the Co grains was clearly observed when the rapidly solidified particles were annealed at $1173 \mathrm{~K}$ under $10 \mathrm{~T}$. The average angle between the long-axis and the magnetic field direction at $10 \mathrm{~T}$ is 15 degrees smaller than the average value at $0 \mathrm{~T}$. The coarsening model suggested that the shape magnetic anisotropy energy acts as a driving force of the coarsening in the region that the Co grain size is several $\mu \mathrm{m}$. The static magnetic energy due to the shape anisotropy has an alternative potential to produce the aligned structure.
\end{abstract}

KEY WORDS: magnetic anisotropy; shape anisotropy; coarsening; copper-cobalt alloy.

\section{Introduction}

Application of a magnetic field to solidification processing has been practically developed, i.e. improvement of the casting process has been realized for the continuous steel casting. ${ }^{1)}$ Imposition of the static magnetic field reduces turbulence in the melt flow, while the alternating magnetic field is used for stirring of the melt. Both of them attributed to the Lorentz force. Magnitude of the static magnetic field is typically less than $1 \mathrm{~T}$.

Another effect of the magnetic field is the static magnetic energy and the magnetization force that is derived from the static magnetic energy. There are two different anisotropies in the static magnetic energy. One is the crystalline magnetic anisotropy and the other is shape anisotropy. The magnetization force due to the crystalline magnetic anisotropy has been recognized for the paramagnetic and diamagnetic materials under a high magnetic field. For example, many researches on textured structure of the high Tc superconductors have been examined by using anisotropy of the magnetic susceptibility. ${ }^{2-10)}$ Rango et al. ${ }^{11)}$ firstly reported that magnetically aligned structure of $\mathrm{Y}-\mathrm{Ba}-\mathrm{Cu}-\mathrm{O}$ systems was obtained by melt processing under a high magnetic field, while magnetic alignment of YBCO particles in suspension of organic substances was studied. ${ }^{2,12)}$ Effect of the shape anisotropy has been realized in the transformation from the paramagnetic fcc-phase to the ferromagnetic bcc-phase for steels. ${ }^{413)}$ The studies reported that the transforming nuclei in a magnetic field did not exhibit any anisotropy. The dipolar interaction between the ferromagnetic grains resulted in the alignment of the steel microstructure.

Effect of the magnetic field was also realized in the coarsening process from the rapidly solidified $\mathrm{Bi}-\mathrm{Mn}$ al- loys. ${ }^{15)}$ Ferromagnetic BiMn grains were selected during coarsening under the magnetic field of $10 \mathrm{~T}$ in accordance with the crystalline magnetic anisotropy energy of the BiMn crystal. This result indicated that the magnetic field has a potential to produce the aligned structure (crystal orientation and grain shape) through not only the phases transformation but also coarsening in which there is no difference in the constituent phases. However, there is no study on the shape anisotropy induced by the magnetic field during the macroscopic coarsening stage. This paper focuses on the grain shape anisotropy induced by the static magnetic field during coarsening.

The $\mathrm{Co}$ particle in the $\mathrm{Cu}-\mathrm{Co}$ system exhibits cubic structure at temperatures above $695 \mathrm{~K}$, and is a ferromagnet with a rather small crystalline magnetic anisotropy. This system is a suitable system to examine the influence of the magnetic field on the coarsening process of the ferromagnetic grains, since $\mathrm{Cu}$ matrix is a paramagnetic. Some studies have been performed to investigate the influence of magnetic field on precipitation of the Co particles in the $\mathrm{Cu}$ matrix. ${ }^{16-19)} \mathrm{Co}$ particles in dilute $\mathrm{Cu}-\mathrm{Co}$ alloys, tended to elongate to the [100] direction parallel to the imposed magnetic filed during precipitating of the Co particles in $\mathrm{Cu}$ matrix. In these studies, size of the precipitating Co particles was the order of $10^{-7} \mathrm{~m}$ at most.

It is also interesting to investigate the influence of the magnetic field on the growth of the Co grains after the Co particles precipitated. It is, however, difficult to observe the coarsening process in dilute alloys. Thus, the microstructure in which fine Co grains uniformly distribute in the $\mathrm{Cu}-\mathrm{Co}$ alloys with higher $\mathrm{Co}$ concentration is desirable to examine the coarsening process in the magnetic field. Figure 1 shows phase diagram of the $\mathrm{Co}-\mathrm{Cu}$ system. ${ }^{20)}$ The 


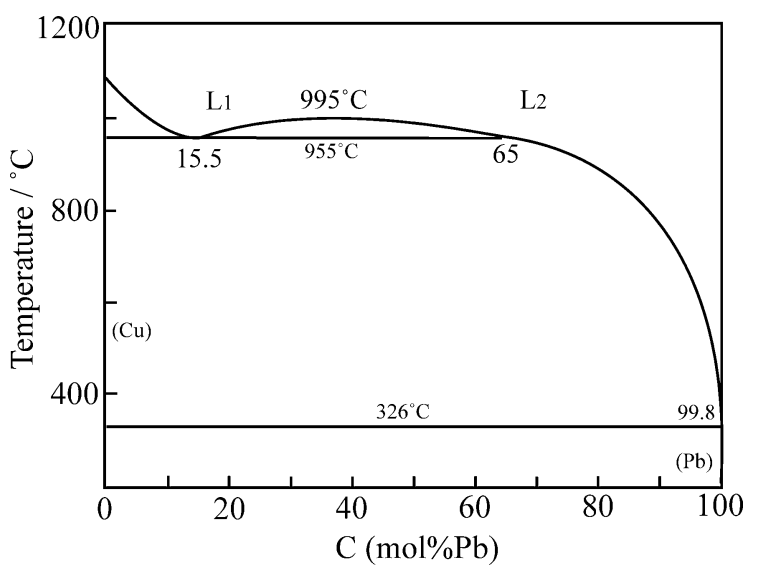

Fig. 1. Phase diagram of $\mathrm{Co}-\mathrm{Cu}$ system. ${ }^{20)}$

$\mathrm{Cu}-\mathrm{Co}$ system shows a shallow liquidus line in the wide composition range. It has been reported that two liquid phase separation occurs in the undercooled melt. ${ }^{21-28)}$ It is expected to obtain the microstructure in which fine Co grains are uniformly distributed when the two liquid phase separation occurs and rapidly solidifies. This paper shows the influence of the magnetic field on the coarsening process of the fcc-Co grains with a small crystalline magnetic anisotropy. The mechanism of the anisotropic microstructure evolution is also discussed.

\section{Experimental Procedures}

$\mathrm{Cu}$ and $\mathrm{Co}$ of the grade $99.9 \%$ were melted in the vacuum atmosphere in the induction furnace, and the $\mathrm{Cu}-$ 30 at $\%$ Co mother alloy was made by metal mold casting. The rapidly solidified particles were made by using a rotating-water-atomization equipment. ${ }^{29)}$ The mother alloy was put into the silica nozzle, it was melted by the inductionheating device and then was injected into a water layer in the rotating drum. The particles were rapidly solidified in the water. The rapidly solidified particles were dries in the vacuum after they were collected from the water and were washed with the ethanol. The particles were classified into diameters. The rapidly solidified particles of which diameters were $250 \mu \mathrm{m}$ or less were pressed at room temperature under $350 \mathrm{MPa}$ to produce a compact $(6 \mathrm{~mm}$ in diameter, $2 \mathrm{~mm}$ in height). The specimens inserted in the graphite sample holder were enclosed in the argon atmosphere of $10^{4} \mathrm{~Pa}$ in a silica tube. The annealing under the magnetic field was performed in the furnace set up in the bore of the He-free superconducting magnet. Intensity of the imposed magnetic field is 0 and $10 \mathrm{~T}$. The anneal temperature was $1173 \mathrm{~K}$, and after annealing, the specimen was cooled in the magnetic field until temperature became $573 \mathrm{~K}$. According to the phase diagram of the $\mathrm{Cu}-\mathrm{Co}$ system, the $\mathrm{Cu}-$ rich phase and the Co-rich phase are solid at the anneal temperature $(1173 \mathrm{~K})$, and the Co phase is a ferromagnet.

The microstructure of $\mathrm{Cu}-\mathrm{Co}$ alloy was observed by a conventional SEM using an EDX image. The feature of the Co grain shape was evaluated from the microstructure in the cross section which was parallel to the imposed magnetic field. The shape of the Co crystal grain in the cross section was approximated to the ellipse. Figure 2 shows a

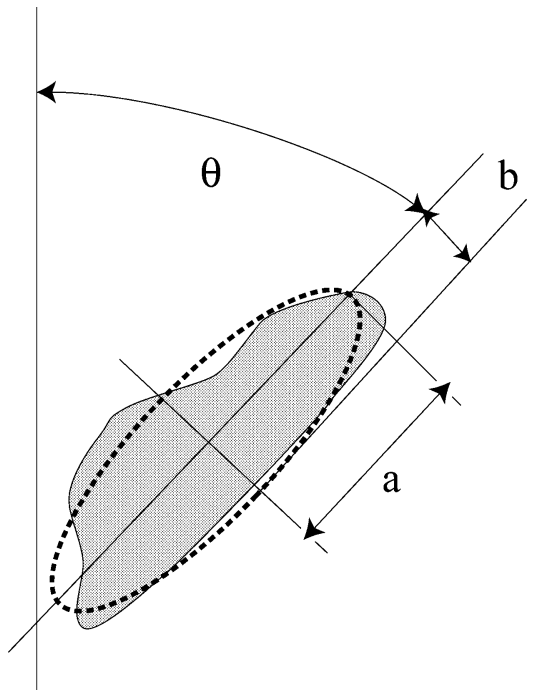

Fig. 2. Schematic illustration of the image analysis to evaluate the anisotropy of the coarsened $\mathrm{Co}$ grains in the $\mathrm{Cu}-\mathrm{Co}$ alloys. The Co grain (solid line) is approximated an ellipse shape (dash line). Lengths of the long-axis and short-axis are defined as a and b, respectively. The angle between the Magnetic field and the long-axis direction is defined as $\theta$.

schematic illustration of the particle shape analysis. The angle $\theta$ is defined by the angle between the magnetic field and the long axis of the elliptic particle. The ratio of the short axis to the long axis is defined as $m$. The magnetization curves of the $\mathrm{Cu}-30$ at\% Co alloys were measured in two directions, and the anisotropy of the magnetization was examined. One is the direction that is parallel to the magnetic field imposed during annealing, and the other is the direction that is perpendicular to the imposed magnetic field.

\section{Experimental Results}

\subsection{Microstructure of the Rapidly Solidified $\mathrm{Cu}-$ 30 at $\%$ Co Alloys}

Figure 3 shows the microstructures of the $\mathrm{Cu}-30 \mathrm{at} \% \mathrm{Co}$ mother alloy and the rapidly solidified particles. The dendrite of the Co-rich primary phase was observed in the cast mother alloys. Rather large Co-rich phase of which size was more than $10 \mu \mathrm{m}$ was observed in the rapidly solidified particles of which diameter ranged from 470 to $710 \mu \mathrm{m}$. In the rapidly solidified particles of $250-420 \mu \mathrm{m}$ in diameter, the coarse Co-rich phase was still observed in a part of the particles. On the other hand, the microstructure in which fine Co grains with diameter of several $\mu \mathrm{m}$ were uniformly distributed in the $\mathrm{Cu}$ matrix was observed in the rapidly solidified particles of which diameter was $250 \mu \mathrm{m}$ or less.

The grain size dependence on the microstructure originates in the cooling rate. In the case of the lager particles injected into the water layer, the cooling rate was not so high and then the dendritic growth of primary Co occurs in accordance with the equilibrium phase diagram. The cooling rate increases as the particle size becomes small. As a result, the melt temperature became below the metastable immiscibility dome of the two liquid phases (Cu-rich and Co-rich liquid phases), and consequently the liquid phase 

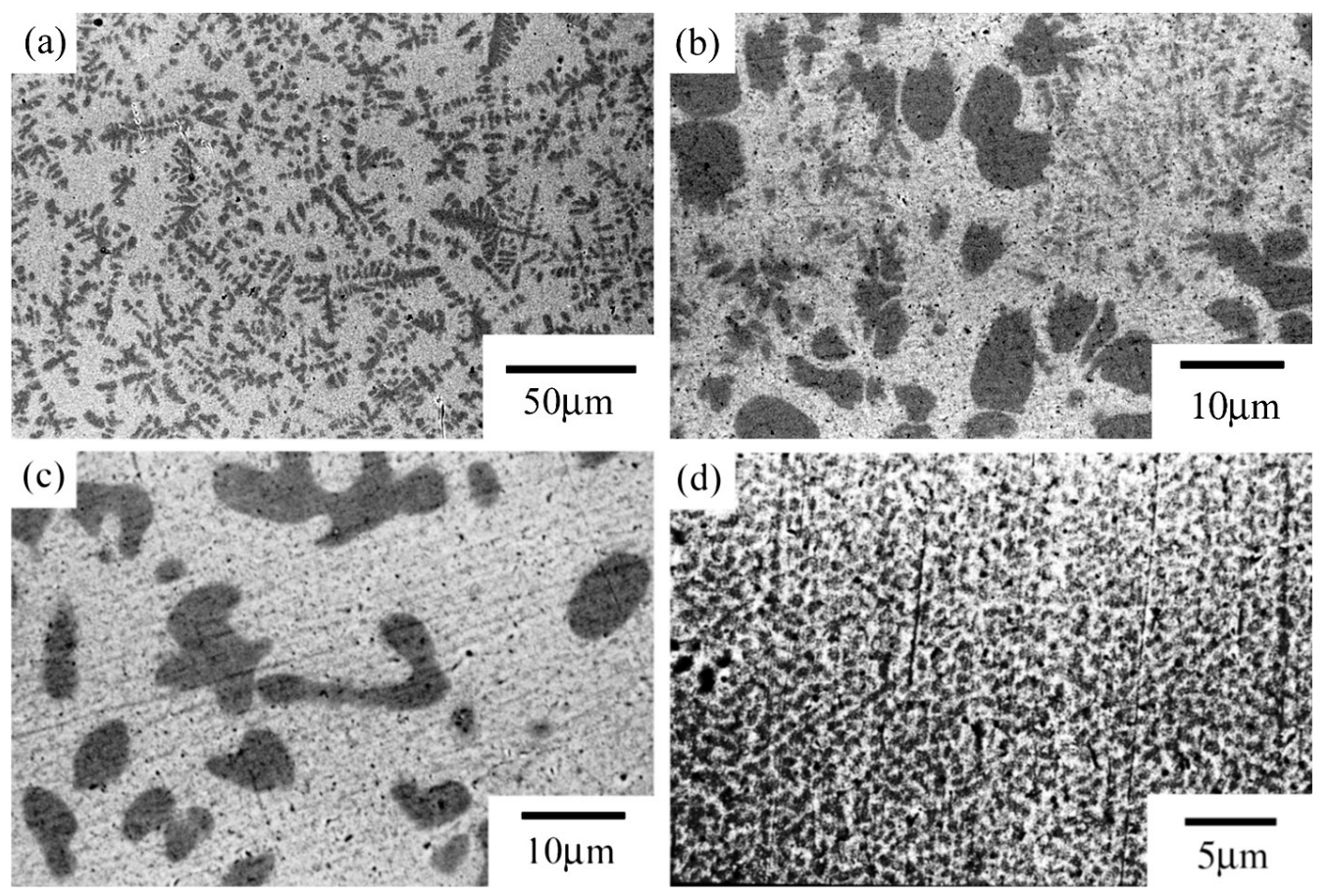

Fig. 3. Microstructures of the $\mathrm{Cu}-30$ at $\%$ Co alloys. (a) Mother alloys cast in metal mold, (b) the rapidly solidified particles (diameter: $470-710 \mu \mathrm{m}$ ), (c) rapidly solidified particles (diameter: $250-470 \mu \mathrm{m}$ ), (d) rapidly solidified particles (diameter: $<250 \mu \mathrm{m}$ ).

separation occurs in the melt. In the state of the liquid phase separation, the minor phase tends to be spherical, reducing the total interfacial energy. Thus, the rapid solidification of the two-liquid state causes the uniform distribution of the minor phase in the matrix, since the Co-rich liquid phase is isolated by the $\mathrm{Cu}$-rich liquid phase. The microstructure observed in the rapidly solidified specimens with the diameters less than $250 \mu \mathrm{m}$ suggested that the liquid phase separation contributed to the formation of the fine and uniform Co particles of which size was typically $1 \mu \mathrm{m}$ or less. Since the fine and uniform Co grains are suitable to examine the coarsening process, the rapidly solidified particles of which diameter was less than $250 \mu \mathrm{m}$ was used to examine the influence of the magnetic field on the shape of the coarsened Co grains.

\subsection{Influence of the Magnetic Field on Shape of the Co Grains}

Figure 4 shows microstructures in the cross section parallel to the imposed magnetic field after the rapidly solidified particles with diameters less than $250 \mu \mathrm{m}$ were annealed at $1173 \mathrm{~K}$ for $4 \mathrm{~h}, 12 \mathrm{~h}, 48 \mathrm{~h}$ and $200 \mathrm{~h}$ under a magnetic field of $0 \mathrm{~T}$ or $10 \mathrm{~T}$. Horizontal direction in the photograph corresponds to the magnetic field direction imposed during annealing. The Co grains slightly coarsened, but the influence of the magnetic field was not clear for the specimens annealed for $4 \mathrm{~h}$ and $12 \mathrm{~h}$. The Co grains grew up to about $5 \mu \mathrm{m}$ by annealing the specimens for $48 \mathrm{~h}$. Although no influence of the magnetic field on the size of the Co grains was observed for the specimens annealed under magnetic fields of $0 \mathrm{~T}$ and $10 \mathrm{~T}$, influence of the magnetic field on the shape of the Co grains was realized as shown in Fig. 4. There was a tendency that the Co grains elongated in the direction parallel to the imposed magnetic field direction during the annealing under the magnetic field.

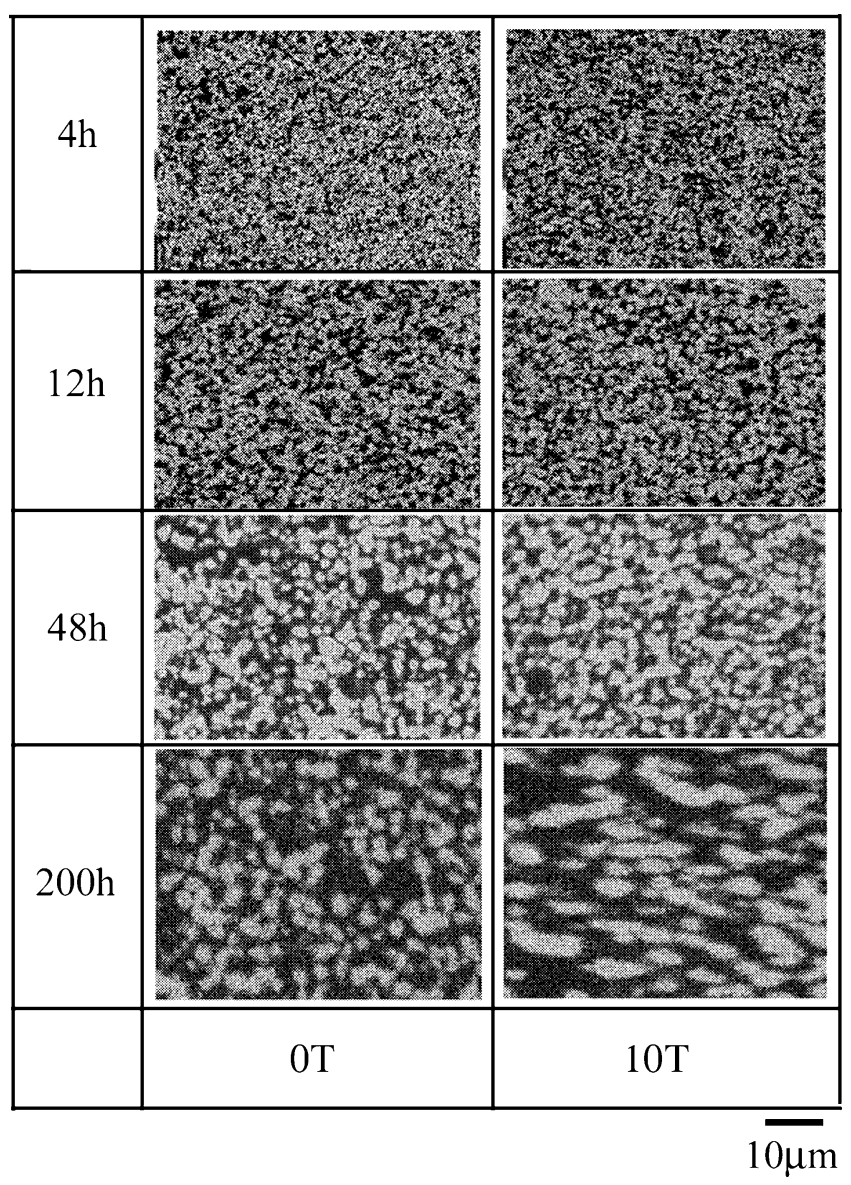

Fig. 4. Microstructure of the cross section parallel to the imposed magnetic field for the $\mathrm{Cu}-30 \mathrm{at} \% \mathrm{Co}$ alloys. Magnetic field was imposed in the horizontal direction of the photographs. 

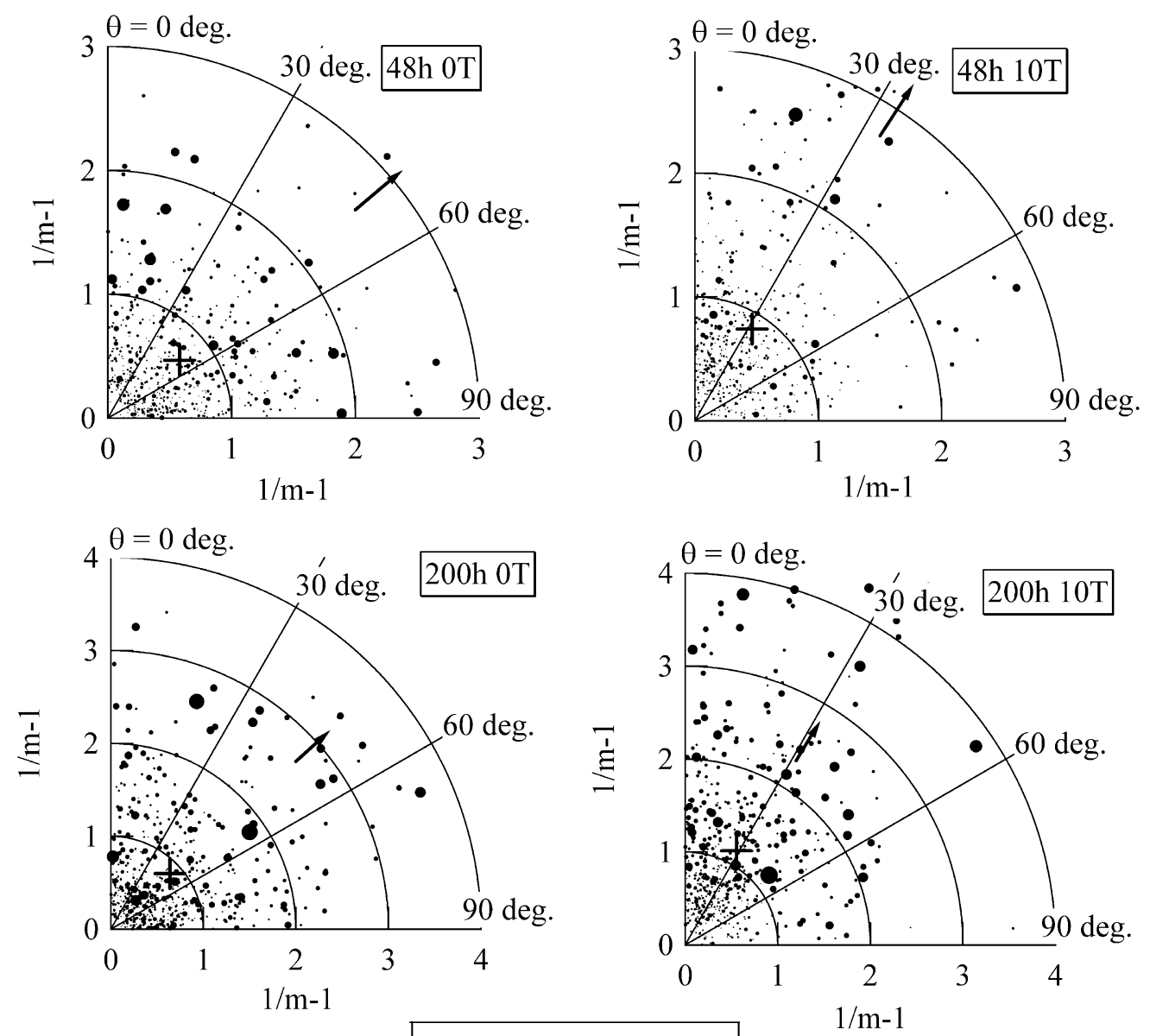

$$
\begin{array}{|cc|}
\hline \begin{array}{c}
<.5 \mu \mathrm{m}^{2} \\
\text { - } 15 \mu \mathrm{m}^{2}
\end{array} & \bullet 22.5 \mu \mathrm{m}^{2} \\
\hline
\end{array}
$$

Fig. 5. Shape of the Co grains as a function of the angle between the imposed magnetic field and the long-axis direction, and the spheroidicity " $1 / m-1$ ". The $m$ is defined by $b / a$. Here, $a$ and $b$ are lengths of the long-axis and the short axis, respectively. Size of the marks indicate the cross sectional area of the Co grains.

The influence of the magnetic field on the shape of the Co grain became obvious in the specimens annealed for $200 \mathrm{~h}$ at $1173 \mathrm{~K}$. In the specimen annealed without the magnetic field, the shape of the Co grains was almost a circle. When the magnetic field of $10 \mathrm{~T}$ was imposed during the annealing for $200 \mathrm{~h}$, the Co grains clearly elongated in the magnetic field direction. Moreover, the microstructure suggested that the Co grains aligned in the magnetic filed direction preferably coarsened together and connected with each other.

The shape anisotropy of the ferromagnetic Co grains coarsened under the magnetic field was quantitatively evaluated. Figure 5 shows results of the analysis for the $\mathrm{Cu}-30 \mathrm{at} \% \mathrm{Co}$ alloys annealed for $48 \mathrm{~h}$ and $200 \mathrm{~h}$ at $1173 \mathrm{~K}$. The Co grains are plotted as a function of the angle, $\theta$ between the magnetic field and the long-axis direction of the approximated ellipse and the ratio of the short-axis length to the long-axis length. Size of the plotted marks is proportional to the grain size. The value of " $1 / m-1$ " is a parameter to express the spheroidicity. For example, the value is 0 for the circle and it increases with decreasing spheroidicity. The arrows in the graphs are a mean value of the angle, and the cross sign indicates the average value of " $1 / m-1$ ". In the specimen annealed without imposing the magnetic field, the direction of the long-axis of the Co particle was ran- dom, while the angle $\theta$ approached 0 deg for the specimens annealed under the magnetic field. Furthermore, the Co grains with relatively large size tended to exhibit large values of $t$ " $1 / m-1$ ". It indicated that the Co grains growing under the magnetic field elongated in the direction of the magnetic field imposed during the annealing.

Figure 6 shows the distribution of the angle $\theta$ for the Co grains in the specimens annealed under the magnetic field. In the specimens annealed without the magnetic field, number of the Co grains increased with increasing the angle, indicating that random distribution of the long-axis direction. On the other hand, the Co grains obviously gathered in the low angle region for the specimens annealed under the magnetic field. Especially, large Co grains placed in the low angle region. The average angles in the specimens annealed without the magnetic field were $50.4 \mathrm{deg}(12 \mathrm{~h}), 50.0 \mathrm{deg}$ $(48 \mathrm{~h})$, and $47.9 \mathrm{deg}(200 \mathrm{~h})$. For the specimens annealed under the magnetic field of $10 \mathrm{~T}$, the average angles were $37.2 \mathrm{deg}(12 \mathrm{~h}), 33.1 \mathrm{deg}(48 \mathrm{~h})$ and $31.2 \mathrm{deg}(200 \mathrm{~h}$.). The quantitative analysis of the Co grain shape clearly indicated that the Co grains elongated to the magnetic field direction.

\subsection{Magnetization of the $\mathrm{Cu}-\mathrm{Co}$ Alloys Annealed under the Magnetic Field}

Figure 7 shows the result of the magnetization measure- 

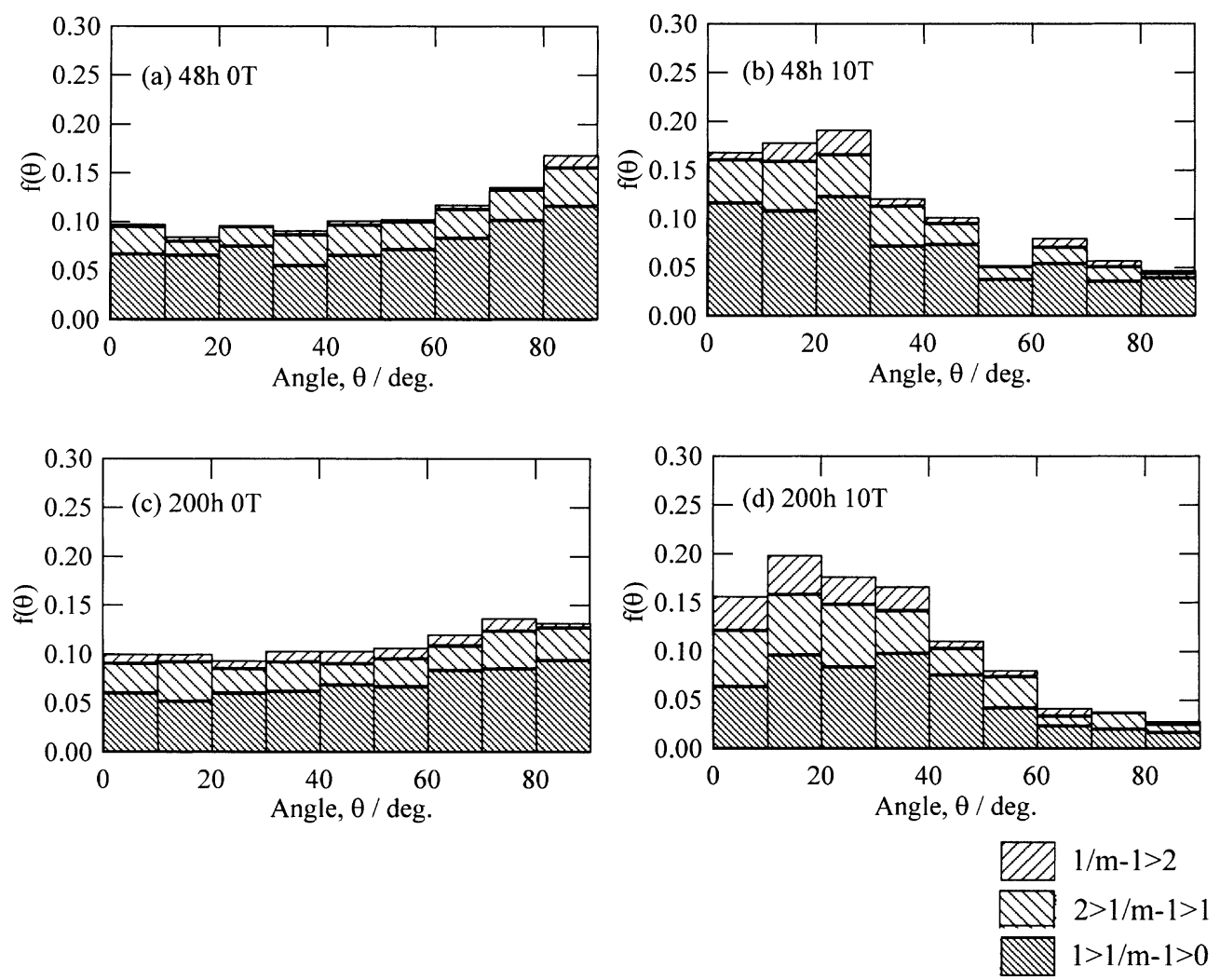

Fig. 6. Distribution of the angle between the magnetic field and the long-axis direction of the $\mathrm{Co}$ grains in the $\mathrm{Cu}-$ 30at $\%$ Co alloys. (a) $48 \mathrm{~h}, 0 \mathrm{~T}$, (b) $48 \mathrm{~h}, 10 \mathrm{~T}$, (c) $200 \mathrm{~h}, 0 \mathrm{~T}$ and (d) $200 \mathrm{~h}, 10 \mathrm{~T}$. The filled patterns indicate the spheroidicity, $m$.
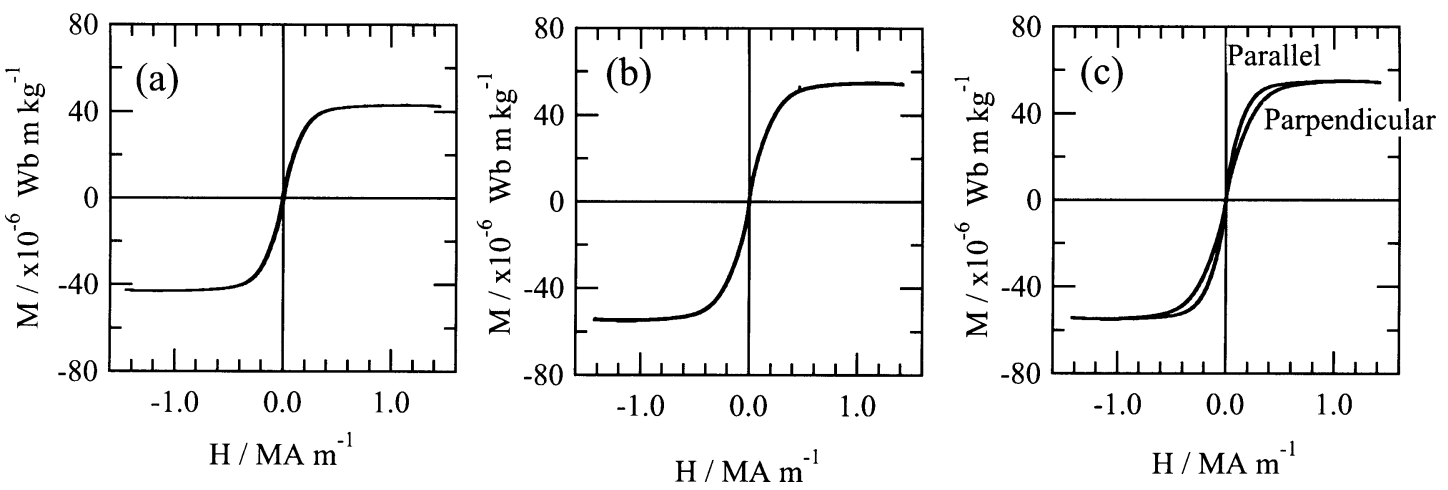

Fig. 7. Magnetization curves of the $\mathrm{Cu}-30 \mathrm{at} \% \mathrm{Co}$ alloys. (a) Rapidly solidified particles (diameter $<1 \mu \mathrm{m}$ ), (b) annealed at $1173 \mathrm{~K}$ for $200 \mathrm{~h}$ under $0 \mathrm{~T}$ and $(\mathrm{c})$ annealed at $1173 \mathrm{~K}$ for $200 \mathrm{~h}$ under $10 \mathrm{~T}$.

ment for the $\mathrm{Cu}-30 \mathrm{at} \% \mathrm{Co}$ alloys. Notation such as "Parallel" and "Perpendicular" indicates the configuration between the imposed magnetic field for the magnetization measurement and the magnetic field direction imposed during the annealing. The anisotropy was not observed in the magnetization curves in the rapidly solidified particles (Fig. 7(a)). Since the $\mathrm{Co}$ was supersaturated in the $\mathrm{Cu}$ matrix for the rapidly solidified particles, the saturated magnetization that is proportional to content of the Co phase was slightly smaller than that for the annealed specimens (Fig. 7(b)). On the other hand, the saturated magnetization of the annealed specimen was approximately $5.4 \times 10^{-5} \mathrm{~Wb} \mathrm{~m} / \mathrm{kg}$ regardless of the time of annealing or the intensity of the magnetic field, as shown Figs. 7(b) and 7(c). It indicates that the amount of the Co phase was not affected by the imposed magnetic field. Any anisotropy in the magnetization curves was not realized for the specimen annealed without the magnetic field (Fig. 7(b)), while the anisotropy was clearly detected for the specimens annealed under the magnetic field of $10 \mathrm{~T}$ (Fig. 7(c)). For the specimens annealed under the magnetic field, easy direction of the magnetization coincided with the magnetic field direction during the annealing as shown in Fig. 6(c).

Figure 8 shows the saturated magnetization and the induced anisotropy energy estimated from the magnetization curves as a function of the annealing time. The area enclosed by the two magnetization curves ("parallel" and "perpendicular") in Fig. 7(c) corresponds to the magnetic anisotropy energy induced by the annealing under the magnetic field. The anisotropy energy was estimated by integrating the gap between the two curves from $0 \mathrm{~A} / \mathrm{m}$ to $1.43 \mathrm{MA} / \mathrm{m}$, since the magnetization in both of the two di- 


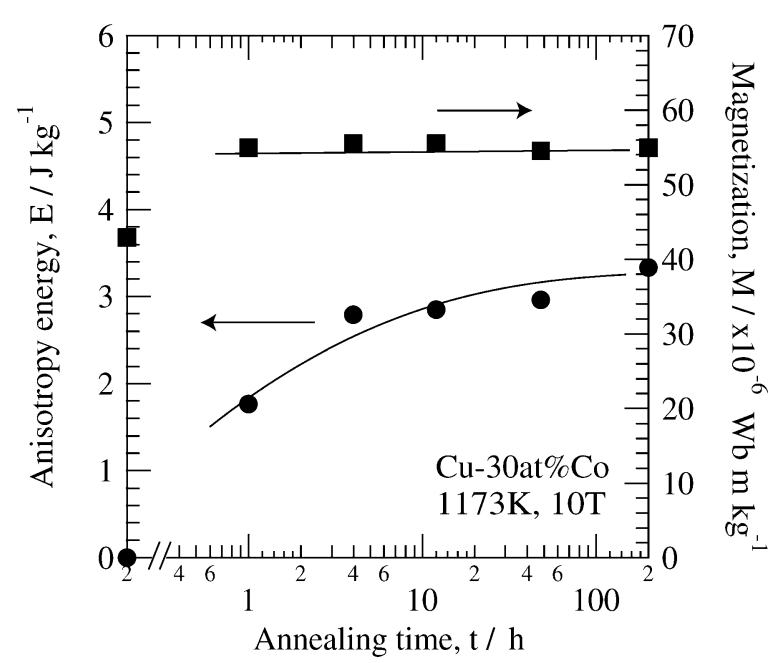

Fig. 8. Saturated magnetization and the magnetic anisotropy energy estimated from the magnetization curves for the $\mathrm{Cu}-30$ at $\%$ Co alloys annealed at $1173 \mathrm{~K}$ under $10 \mathrm{~T}$.

rections saturated before $1.43 \mathrm{MA} / \mathrm{m}$. The saturated magnetization did not change after the specimens were annealed for $1 \mathrm{~h}$. The precipitation of Co completed before the annealing time of $1 \mathrm{~h}$. The anisotropy energy estimated from the magnetization curves rapidly increased until the annealing time of $4 \mathrm{~h}$. After annealing for $4 \mathrm{~h}$, the magnetic anisotropy energy continued to increase slightly. The slightly increase corresponds to the anisotropic shape formation of Co grains. Therefore, the induced magnetic anisotropy is related to not the precipitation of Co but the coarsening of Co grains.

\section{Discussion}

It is necessary to compare the crystalline magnetic anisotropy energies with the shape anisotropy energy to examine the formation of anisotropy shape of the fcc-Co grains in the coarsening process under the magnetic field. Crystalline magnetic anisotropy energy $E_{\text {crystal }}$ of the fcc-Co grain is express by the following equation. ${ }^{30}$ )

$$
E_{\text {crystal }}=K_{1}\left(\alpha_{1}^{2} \alpha_{2}^{2}+\alpha_{2}^{2} \alpha_{3}^{2}+\alpha_{3}^{2} \alpha_{1}^{2}\right)+K_{2} \alpha_{1}^{2} \alpha_{2}^{2} \alpha_{3}^{2}
$$

Here, $K_{1}$ and $K_{2}$ are the magnetic anisotropy constants. The $\alpha_{1}, \alpha_{2}$, and $\alpha_{3}$ are the cosines of the direction of the spontaneous magnetization and [100], [010], and [001] directions, respectively. The equation was developed using the cosines so that the expression of the anisotropy energy satisfies the crystal symmetry of the cubic structure. $K_{1}$ and $K_{2}$ of the Co crystal are estimated to be $0.9 \mathrm{~kJ} / \mathrm{m}^{3}$ and $5.7 \mathrm{~kJ} / \mathrm{m}^{3}$, respectively, at the annealing temperature of $1173 \mathrm{~K}^{31)}$ On the other hand, the shape anisotropy energy is assumed to be $10^{2}-10^{3} \mathrm{~kJ} / \mathrm{m}^{3}$ when one assumes that the magnetization $M_{\mathrm{p}}$ of the fcc-Co phase is $85 \%$ of magnetization 1.57 $\mathrm{Wb} / \mathrm{m}^{2}$ at room temperature ${ }^{31)}$ and the difference of the demagnetizing factor is 0.33 . For the fcc-Co grains at the anneal temperature, the shape magnetic anisotropy is about $10^{3}$ times as large as the crystalline magnetic anisotropy. Therefore, it is expected that the microstructure changes due to the shape anisotropy occur in the $\mathrm{Cu}-\mathrm{Co}$ system.

A model on the formation of an anisotropy grain during the coarsening process is presented when the crystalline magnetic anisotropy energy is ignored. For simplicity, the model deals with a ferromagnetic particle with the spheroid shape which is isolated by the non-magnetic matrix. Lengths in the rotational axis and in the direction perpendicular to the rotational axis are $a$ and $b$, respectively. The ratio $\mathrm{m}$ is defined by $b / a$. The factors, which contribute to the shape change, are the shape anisotropy energy and the surface energy in the present model.

Magnetic energy $U_{\mathrm{m}}$ that contains the shape magnetic anisotropy is given by

$$
U_{\mathrm{m}}=-M_{\mathrm{p}}\left(H_{\mathrm{ex}}-\frac{N_{\mathrm{d}} M_{\mathrm{p}}}{\mu_{0}}\right)
$$

Here, $M_{\mathrm{p}}$ is magnetization, $H_{\mathrm{ex}}$ is an external magnetic field, $N_{\mathrm{d}}$ is a demagnetizing factor, and $\mu_{0}$ is the magnetic permeability in vacuum. Free energy $G$ of the system including the magnetic energy and the surface energy is expressed by

$$
\begin{aligned}
G= & (N-n) \cdot v_{\text {mole }} \cdot\left\{H_{\mathrm{m}}-T S_{\mathrm{m}}\right\}+n \cdot v_{\text {mole }} \cdot\left\{H_{\mathrm{p}}-T S_{\mathrm{p}}\right\} \\
& +s_{\mathrm{p}} \cdot \sigma-n \cdot v_{\text {mole }} \cdot M_{\mathrm{p}}\left(H_{\mathrm{ex}}-\frac{N_{\mathrm{d}} M_{\mathrm{p}}}{\mu_{0}}\right) \\
= & N \cdot v_{\mathrm{mole}} \cdot\left\{H_{\mathrm{m}}-T S_{\mathrm{m}}\right\}-v_{\mathrm{p}} \cdot\left(\Delta H_{\mathrm{m}-\mathrm{p}}-T \Delta S_{\mathrm{m}-\mathrm{p}}\right\} \\
& +s_{\mathrm{p}} \cdot \sigma-v_{\mathrm{p}} \cdot M_{\mathrm{p}}\left(H_{\mathrm{ex}}-\frac{N_{\mathrm{d}} M_{\mathrm{p}}}{\mu_{0}}\right) \ldots \ldots \ldots \ldots \ldots \ldots \ldots \ldots \ldots \ldots \ldots \ldots \ldots \ldots \ldots
\end{aligned}
$$

Here,

$$
\begin{aligned}
& v_{\mathrm{p}}=n \cdot v_{\text {mole }} \\
& \Delta H_{\mathrm{m}-\mathrm{p}}=H_{\mathrm{m}}-H_{\mathrm{p}} \\
& \Delta S_{\mathrm{m}-\mathrm{p}}=S_{\mathrm{m}}-S_{\mathrm{p}}
\end{aligned}
$$

$N$ is total moles of the system, $n$ is the moles of the ferromagnetic particles, and $v_{\mathrm{m}}$ is the molar volume of the matrix and the particles (for simplicity, the same molar volume were used for both phases). $H$ and $S$ are enthalpy and entropy, respectively, and the subscripts indicate the matrix (m) and the particle (p). The interfacial energy is $\sigma$. The volume and the interfacial area of the ferromagnetic particle are $v_{\mathrm{p}}$ and $s_{\mathrm{p}}$, respectively. In this case, the local equilibrium condition between the particle and the matrix is given by the following equation.

$$
\left(\frac{\partial G}{\partial v_{\mathrm{p}}}\right)_{T, N_{\mathrm{d}}}=0
$$

Equations (3) and (5) give Eq. (6).

$$
\begin{aligned}
T= & \left\{\frac{\Delta H_{\mathrm{m}-\mathrm{p}}}{\Delta S_{\mathrm{m}-\mathrm{p}}}\right\}-\left(\frac{d s_{\mathrm{p}}}{d v_{\mathrm{p}}}\right) \cdot\left(\frac{\sigma}{\Delta S_{\mathrm{m}-\mathrm{p}}}\right) \\
& +\frac{M_{\mathrm{p}}}{\Delta S_{\mathrm{m}-\mathrm{p}}}\left(H_{\mathrm{ex}}-\frac{N_{\mathrm{d}} M_{\mathrm{p}}}{\mu_{0}}\right) \ldots \ldots . .
\end{aligned}
$$

In this expression, it is assumed that the imposed magnetic field is sufficiently large to saturate the magnetization. In the present study, the imposed magnetic field was $10 \mathrm{~T}$. Thus, the assumption is valid. A sufficiently large sphere of the ferromagnetic particle is defined as the standard condi- 
tion. The value of $\left(d s_{\mathrm{p}} / d v_{\mathrm{p}}\right)$ becomes 0 because radius of the curvature is large enough in this standard condition. The local equilibrium temperature of the standard condition is defined as $T_{\text {std. }}$ Temperature deviation, $\Delta T$, from the equilibrium temperature of the standard condition is given by

$$
\begin{aligned}
\Delta T & =T-T_{\text {std }} \\
& =-\left(\frac{d s_{\mathrm{p}}}{d v_{\mathrm{p}}}\right) \cdot\left(\frac{\sigma}{\Delta S_{\mathrm{m}-\mathrm{p}}}\right)-\left(N_{\mathrm{d}}-N_{\mathrm{d}}^{0}\right) \frac{M_{\mathrm{p}}^{2}}{\mu_{0} \Delta S_{\mathrm{m}-\mathrm{p}}} \ldots \ldots . .
\end{aligned}
$$

Here, the demagnetizing factor $N_{\mathrm{d}}^{0}$ is equal to $1 / 3$. Therefore, $\Delta T$ is a parameter to express thermodynamic stability of the particle, and it corresponds to the driving force in the coarsening. In other words, any shape change results in increase of $\Delta T$ defined by Eq. (7).

Surface area and curvature $\left(d s_{\mathrm{p}} / d v_{\mathrm{p}}\right)$ of the spheroid is derived from the geometric consideration. Volume $v_{\mathrm{p}}$ of the spheroid is given by

$$
v_{\mathrm{p}}=\frac{4}{3} \pi a b^{2}=\frac{4}{3} \pi m^{2} a^{3}
$$

Surface area $s$ is given by

$$
\begin{array}{rlr}
s_{\mathrm{p}} & =2 \pi m^{2} a^{2}+\frac{2 \pi m a^{2}}{\sqrt{1-m^{2}}} \sin ^{-1} \sqrt{1-m^{2}} \quad(m<1) \\
& =4 \pi a^{2} \quad(m=1) \\
& =2 \pi m^{2} a^{2}+\frac{2 \pi m a^{2}}{\sqrt{m^{2}-1}} \ln \left(\sqrt{m^{2}-1}+m\right) \quad(m>1) \ldots
\end{array}
$$

In addition, the curvature is defined by the following equation in this study.

$$
\left(\frac{d s_{\mathrm{p}}}{d v_{\mathrm{p}}}\right)_{\mathrm{m}}=\left(\frac{d s_{\mathrm{p}}}{d a}\right)_{\mathrm{m}}\left(\frac{d a}{d v_{\mathrm{p}}}\right)_{\mathrm{m}}=\frac{1}{4 \pi m^{2} a^{2}}\left(\frac{d s_{\mathrm{p}}}{d a}\right)_{\mathrm{m}}
$$

Therefore,

$$
\begin{array}{rlr}
\left(\frac{d s_{\mathrm{p}}}{d v_{\mathrm{p}}}\right)_{\mathrm{m}} & =\frac{1}{a}\left(1+\frac{1}{m \sqrt{1-m^{2}}} \sin ^{-1} \sqrt{1-m^{2}}\right) \quad(m<1) \\
& =\frac{2}{a} \quad \quad(m=1) \\
& =\frac{1}{a}\left(1+\frac{1}{m \sqrt{m^{2}-1}} \ln \left(\sqrt{m^{2}-1}+m\right)\right)(m>1)
\end{array}
$$

On the other hand, the demagnetizing factor $N_{\mathrm{d}}$ of the spheroid is given by

$$
\begin{array}{rlrl}
N_{\mathrm{d}} & =\frac{m^{2}}{1-m^{2}}\left[\frac{1}{\sqrt{1-m^{2}}} \ln \left(\frac{1}{m}+\frac{1}{m} \sqrt{1-m^{2}}-1\right)\right](m<1) \\
& =\frac{1}{3} & (m=1) \\
& =1-\frac{1}{m^{2}-1}\left[\frac{m^{2}}{\sqrt{m^{2}-1}} \cos ^{-1}\left(\frac{1}{m}\right)-1\right] & (m>1)
\end{array}
$$

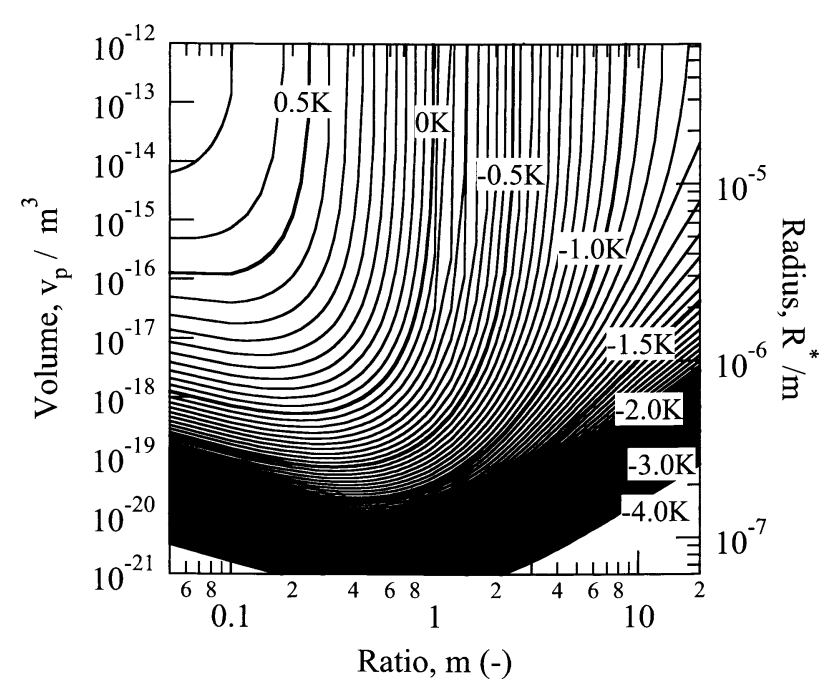

Fig. 9. Temperature deviation, $\Delta T$, from the local equilibrium, defined by Eq. (7), as a function of volume of the grain and the spheroidicity, $m$. Equivalent radius, $R_{\text {eq }}$, of the grain is estimated by $\left[a \cdot b^{2}\right]^{1 / 3}=a \cdot m^{1 / 3}$.

The deviation from the local equilibrium temperature at the standard condition is obtained by substituting Eqs. (11) and (12) to Eq. (7).

Figure 9 shows the deviation from the local equilibrium temperature at the standard condition in terms of volume $v_{\mathrm{p}}$ and the ratio $m$ of the ferromagnetic particles. In this calculation, $\sigma=0.1 \mathrm{~J} / \mathrm{m}^{2}$ and $\Delta S_{\mathrm{m}-\mathrm{p}}=10^{6} \mathrm{~J} / \mathrm{m}^{3} \mathrm{~K}$ are used. The surface energy is the same order as the solid-liquid interfacial energy for the metallic alloys, and the entropy change is the same order as that of the fusion. The magnetization of the fcc-Co phase was assumed to be $M=1.5657 \mathrm{~Wb} / \mathrm{m}^{2}{ }^{31}$ )

The isothermal line takes the minimum at $m=1$ and the spherical shape is most stable when the Co grain size is less than $5 \times 10^{-7} \mathrm{~m}$. In a word, the surface energy is predominant in this region. A minimum point of the isothermal line exists in the vicinity of $m=0.2$ when the Co grain size is the order of $10^{-6} \mathrm{~m}$. In this region, the shape anisotropy energy greatly influences the particle shape change during the coarsening under the magnetic field. Furthermore, the shape anisotropy energy is dominant when the size of the grain becomes $10^{-5} \mathrm{~m}$ or more. Therefore, the particles of which sizes are several $\mu \mathrm{m}$ or more are expected to become the anisotropic shape if there is enough time for diffusion. The tendency indicated by the model is qualitatively consistent with the experimental result.

The numerical calculation suggested that the ellipticity, $m$, becomes 0.2 or less for the grains with several $\mu \mathrm{m}$ or more in diameter. The ellipticity, $m$, observed in the experiments is approximately 0.5 even if the specimens were annealed in the magnetic field of $10 \mathrm{~T}$ for $200 \mathrm{~h}$ at $1173 \mathrm{~K}$. The experimental results were smaller than the values expected from the model calculation. There are some possibilities to cause the discrepancy besides inaccuracy of the physical properties. One is shortage of the annealing time to minimize the free energy of the system. The annealing time of $200 \mathrm{~h}$ might be insufficient for solute diffusion in the solid state. Furthermore, the interaction between the particles should be also considered. For example, the Co particle in the $\mathrm{Cu}$ matrix was not completely isolated from 
other Co grains. The interaction may prevent the Co grains from the shape change due to the shape magnetic isotropy energy. For the quantitative evaluation, it is necessary to consider not only the physical properties but also the interaction between the particles.

It is interesting to consider the magnetic interaction between the particles for evolution of the microstructure under the magnetic field. In the case of steel, ${ }^{13,14)}$ the volume fraction of the ferromagnetic ferrite phase is quite high, and it has been pointed out that the magnetic interaction between ferrite grains significantly contributed to the aligned structure formation. The obtained microstructure suggested that the Co grains, which aligned in the magnetic field preferably, grew and connected with each other in the $\mathrm{Cu}-\mathrm{Co}$ alloys, as shown in Fig. 4. The interaction between the particles (dipole-dipole interaction ${ }^{13,14)}$ ) pointed out for the steel system can contributed to the aligned structure in the $\mathrm{Cu}-\mathrm{Co}$ system. However, since the volume fraction of the $\mathrm{Co}$ phase in the $\mathrm{Cu}-\mathrm{Co}$ alloy used in the present study was roughly $30 \%$, the interaction of the particle-particle was not recognized.

It can be said that the interaction between the particles (the dipolar interaction ${ }^{13,14)}$ ) is essentially the same as the shape magnetic anisotropy. For instance, if the grain is assumed to be composed of the fine ferromagnetic elements, the shape magnetic anisotropy is derived from the dipolar interaction between the fine elements. Therefore, effect of the magnetic field on the microstructure evolution controlled by diffusion will be consistently understood by considering the static magnetic energy including not only the external magnetic field but also the interaction between the induced magnetic substances. The phase transformation and the coarsening under the magnetic field have a potential to produce the aligned structure due to the shape magnetic anisotropy.

\section{Conclusions}

This paper examined the shape change of the fcc-Co grains that the crystalline magnetic anisotropy is small at the annealing temperature in the coarsening process from the rapidly solidified structure.

Since the structure change in solid phase is sensitive to the initial microstructure before annealing, uniform and fine microstructure is required as the initial microstructure. In the present experiment, the microstructure in which the fine $\mathrm{Co}$ grains were uniformly distributed in the $\mathrm{Cu}$ matrix, since the liquid phase separation occurred by using the rapid solidification technique. The influence of the magnetic field on the shape change of the Co grains was clearly observed by using the rapidly solidified microstructure in the particles with diameters less than $250 \mu \mathrm{m}$.

It was confirmed that the Co grains grew up to the shape that elongated in the magnetic field direction when the rapidly solidified particles of the $\mathrm{Cu}-30 \mathrm{at} \% \mathrm{Co}$ alloy were annealed under the magnetic field of $10 \mathrm{~T}$ at $1173 \mathrm{~K}$ for $48 \mathrm{~h}$ and $200 \mathrm{~h}$. The mean value of the angle that the direction of the long-axis and the magnetic field direction at $10 \mathrm{~T}$ is 15 degrees smaller than the mean value at $0 \mathrm{~T}$.

The anisotropy structure formation during the coarsening process under the magnetic field was examined from a ther- modynamic aspect. Not only the surface energy but also the shape anisotropy energy acts as a driving force of the coarsening in the region that the Co grain size is several $\mu \mathrm{m}$.

\section{Acknowledgments}

This work is supported in part by a Research for the Future (RFTF) given by Japan Society for the Promotion of Science and by a Grant-in-Aid for Scientific Research of Priority Areas given by the Ministry of Education, Culture, Sports, Science and Technology, Japan. The author expresses his thanks to Toray Science Foundation for the support. This paper also contains fruition from the continuous discussion in a research group "Advanced Application of Electromagnetic Forces to Materials Processing" supported by the technical division of high-temperature processing, ISIJ.

\section{REFERENCES}

1) S. Asai: Sci. Tech. Adv. Mater, 1 (2000), 191.

2) D. E. Farrell, B. S. Chandrasekhar, M. R. Deguire, M. M. Fang, V. G. Kogan, J. R. Chem and D. K. Finnemore: Phys. Rev. B, 36 (1987), 4025 .

3) A. Lusnikov, L. L. Miller, R. W. McCallum, S. Mitra, W. C. Lee and D. C. Johnston: J. Appl. Phys., 65 (1989), 3136.

4) A. Lusnikov, L. L. Miller, R. W. McCallum, S. Mitra, W. C. Lee and D. C. Johnsto: J. Appl. Phys., 65 (1989), 3136.

5) M. R. Lees, D. Bourgault, P. De Rango, P. Leiay, A. Sulpice and R. Tournier: Philos. Mag. B, 65 (1992), 1395.

6) A. Holloway, R. W. MaCallum and S. R. Arrasmith: J. Mater. Res., 8 (1993), 727.

7) P. Courtois, R. P. De La Bahie and R. Tournier: J. Magn. Magn. Mater., 153 (1996), 224.

8) K. Sassa, T. Morikawa and S. Asai: J. Jpn. Inst. Met., 61 (1997), 1283.

9) P. Gillon: Mater. Sci. Eng. A, 287 (2000), 146

10) S. Awaji, K. Watanabe and M. Motokawa: J. Cryst. Growth, 226 (2001), 83.

11) P. de Rango, M. Lees, P. Lejay, A. Sulpice, R. Tournier, M. Ingold, P. Germi and M. Pernet: Nature, 349 (1991), 770.

12) J. E. Tkaczyk and K. W. Lay: J. Mater. Res., 7 (1990), 1368.

13) S. Shimotomai and K. Maruta: Scr. Mater., 42 (2000), 499.

14) K. Maruta and M. Shimotomai: J. Cryst. Growth, 237-239 (2002), 1802.

15) H. Yasuda, I. Ohnaka, K. Shimamura, T. Fukuda and K. Watanabe: Proc. 3rd Int. Symp. on Electromagnetic Processing of Materials, ISIJ, Tokyo, (2000), 647.

16) T. Mitui: J. Phys. Soc. Jpn., 13 (1958), 549.

17) C. W. Berghout: J. Phys. Chem. Solids, 24 (1963), 507.

18) G. Abersfelder, K. Noack, K. Stierstadt, J. Schelten and W. Schatz: Philos. Mag., 41 (1980), 519.

19) T. Fujii, T. Ono and M. Kato: J. Jpn. Inst. Met., 61 (1997), 267.

20) Desk Handbook Phase Diagrams for Binary Alloys, ed. By $\mathrm{H}$. Okamoto, ASM International, Ohio, USA, (2000), 245.

21) M. Shimaoka, I. Ohnaka, I. Yamauchi and M. Maeda: J. Jpn. Inst. Met., 61 (1997), 1115.

22) Y. Nakagawa: Acta Metall., 6 (1958), 704.

23) A. Munitz and R. Abbaschian: J. Mater. Sci., 26 (1991), 6458.

24) A. Munitz, S. P. Elder-Randall and R. Abbaschian: Metall. Trans. A, 23A (1992), 1817.

25) A. Munitz and R. Abbaschian: J. Mater. Sci., 33 (1998), 3639.

26) X. Song, S. W. Mahon, R. F. Cochrane, B. J. Hickey and M. A. Howson: Mater. Lett., 31 (1997), 261.

27) D. Li, M. B. Robinson, T. J. Rathz and G. Williams: Mater. Lett., 36 (1998), 152.

28) Z. Sun, X. Song, Z. Hu, S. Yang, G. Liang and J. Sun: J. Alloys Comp., 319 (2001), 266.

29) I. Ohnaka: T. Fukusako, T. Ohmichi, T. Masumoto, A. Inoue and M. Hagiwara: Proc. 4th Int. Conf. on Rapidly Quenched Metals, Japan Inst. Metals, Sendai, (1981), 31.

30) W. Sucksmith and J. E. Thomson: Porc. R. Soc. (London) A., 225 (1954), 362.

31) Magnetic Properties of Metals (Data in Science and Technology), ed. by H. P. J. Wijn, Springer-Verlag, Berlin, (1991), 13. 